\title{
Thirty years after the fall of the Berlin Wall - Do East and West Germans still differ in their attitudes towards women's employment and the division of housework?
}

\author{
Gundula Zoch ${ }^{\text {a }}$
}

[Accepted and revised version published as: Zoch, Gundula (2021): Thirty Years after the Fall of the Berlin Wall - Do East and West Germans Still Differ in Their Attitudes to Female

Employment and the Division of Housework? In: European Sociological Review, Online first. DOI: 10.1093/esr/jcab002.]

\begin{abstract}
Previous cross-sectional studies show less traditional gender ideologies among East Germans after German reunification and even suggest slightly increasing East-West disparities. These findings challenge the assumptions of stable ideologies over the life-course as well as cohort replacement-based convergence over time. This study expands on previous research by analysing differences and trends in gender ideologies in the context of East and West Germany using data from the German Family Panel pairfam (2008-2018). It distinguishes between three cohorts born in the early 1970s, 1980s and 1990s who have different socialisation experiences before and after reunification. The results show smaller East-West differences in gender ideologies for the youngest cohort compared with larger gaps for the two older cohorts born before reunification. Convergence of ideologies is partly due to modernisation trends in West Germany and re-traditionalisation effects in East Germany across cohorts, but also due to attitudinal changes with age. Attitudes towards housework and female employment have particularly converged, while views on maternal employment and the consequences for children's well-being continue to differ between East and West Germany. The findings underline the importance of persistent, long-lasting ideology differences due to the regimespecific socialisation and composition resulting from the division of Germany, but also emphasizes the role of ideology change across cohorts and over the life-course for the overall converging trends in gender ideologies.
\end{abstract}

Keywords: attitudinal change; attitudinal trends; East and West Germany; gender ideologies, gender role attitudes, life-course effects, regime socialisation

Acknowledgements: The author is grateful for comments on the paper from participants at the ECSR Conference 2019 as well as comments on an earlier version of this paper from those at invited seminars at LIfBi and the WZB.

\footnotetext{
a Gundula Zoch, Leibniz Institute for Educational Trajectories, Wilhelmsplatz 3, 96047

Bamberg, Germany, E-Mail: gundula.zoch@lifbi.de, ORCID iD: 0000-0002-4398-4535
} 


\section{Thirty years after the fall of the Berlin Wall - Do East and West Germans still differ in their attitudes towards women's employment and the division of housework?}

\section{Introduction}

Understanding the formation and change of gender ideologies is crucial as traditional attitudes towards maternal employment and family work are linked to gendered inequalities in the division of paid and domestic work (Davis and Greenstein, 2009). Previous longitudinal studies have highlighted the importance of parent's attitudes and attitude-related behaviour for the socialisation of lasting gender role attitudes and gendered behaviour of their children (Cunningham, 2001b; Farré and Vella, 2013; Platt and Polavieja, 2016). However, little is known whether the institutional context during childhood has a similarly long-lasting influence on gender ideologies.

To investigate the influence of political regime socialisation, and in their search for external variation, numerous studies have exploited the reunification of the formerly divided Germany. During the 40 years of separation, the socialist German Democratic Republic (GDR) and the liberal, democratically oriented Federal Republic of Germany (FRG) supported gender equalities in the labour market and family very differently. Earlier studies therefore unanimously showed that East Germans born before reunification continue to have less traditional gender ideologies after reunification than West Germans (Adler and Brayfield, 1997; Banaszak, 2006; Bauernschuster and Rainer, 2012; Braun, Scott and Alwin, 1994; Lee, Alwin and Tufis, 2007). These findings have confirmed the assumptions about long-lasting ideological differences due to regime-specific socialisation.

Although the differences in attitudes between East and West are expected to persist, it was assumed that the gaps will narrow against the background of similar institutional and political conditions. According to cohort-replacement theory, younger cohorts with more similar socialisation conditions and, thus, similar ideologies replace older cohorts with regime-specific 
attitudes over time (e.g., Baxter et al., 2015; Bolzendahl and Myers, 2004; Brooks and Bolzendahl, 2004). However, some studies point to slightly increasing East-West differences in gender ideologies after reunification (Banaszak, 2006; Bauernschuster and Rainer, 2012; Lee, Alwin and Tufis, 2007). These findings question the assumption of cohort replacementbased convergence and diminishing East-West disparities over time. However, with only repeated cross-sectional data from the General Social Survey, previous studies were unable to disentangle changes in gender ideologies within cohorts from individual-level changes over the life-course. Moreover, as the data did not yet include individuals born after 1970, or only to a limited extent, these studies predominantly focused on older cohorts. It is therefore unclear whether and to what extend East-West differences in gender ideologies are also relevant for younger cohorts born shortly before or after reunification.

This study contributes to the research on the formation and changes in gender ideologies by examining East-West-specific regime-socialisation on gender ideologies in the context of Germany. With its historical regime change, Germany offers the unique opportunity to investigate how different political regimes and opportunity structures in East and West Germany affect the formation of gender ideologies, how persistent these regime influences are and which factors explain possible changes in ideologies over time. The study makes a decisive contribution to the existing literature in two respects: First, it is the first study to examine EastWest differences in gender ideologies using panel data. Secondly, by analysing data from the German Family Panel pairfam (2008-2018), which surveys three cohorts from the early 1970s, 1980s and 1990s, it also expands the focus to examine younger, not yet studied cohorts born shortly before and after German reunification. From a theoretical point of view, the study examines the assumptions of stable ideologies over the life-course and cohort-replacementbased convergence and their role in the development of attitudinal trends in different institutional contexts. 


\section{The Formation of Gender Ideologies}

\section{Intergenerational Transmission of Gender Ideologies}

The intergenerational transmission of gender ideologies is based on children's direct and indirect socialisation experiences with their parents (Davis and Greenstein, 2009). Children directly observe their parents' behaviour and articulated attitudes and, thus, learn about the gendered division of roles and gender role attitudes as suggested by symbolic-interactionist interpretations (Cunningham, 2001b). Besides, parents might pass on their role expectations by involving their children purposively in the household or the care of younger siblings (CorderoComa and Esping-Andersen, 2018; Cunningham, 2001a). Overall, previous studies found statistically significant relationships between parents' and their children's gender ideologies in later adulthood (Cunningham, 2001b; Farré and Vella, 2013; Platt and Polavieja, 2016). The gender-specific behaviour and attitudes of the mother seem to be particularly relevant. For example, working mothers have less time than homemakers, so in addition to their less traditional ideologies, they may also involve their children more in housework, thus passing on the idea of gender roles to a lesser extent. In addition, a few studies point towards the importance of gender ideologies as an important channel for the intergenerational transmission of gendered behaviour with respect to maternal employment (van Putten, Dykstra and Schippers, 2008) and housework (Cordero-Coma and Esping-Andersen, 2018; Cunningham, 2001b).

However, gendered behaviour can deviate considerably from the articulated attitudes. Some studies therefore suggest that the behavioural socialization of parents may be more decisive for the ideology formation of children than their attitudes (Platt and Polavieja, 2016). However, because few data sets contain information on parents' gender ideologies and their gendered behaviour, there is little evidence on the relative importance of behaviour modelling and the intergenerational transmission of gender ideologies. The few available results indicate an additional, lasting and strong relative influence of parents' gender ideologies (Cunningham, 2001b; Platt and Polavieja, 2016). 
A rich literature on stratification and social mobility further suggests that parents pass on their gender ideologies to their children through an intergenerational transfer of resources and demographic characteristics (Cunningham, 2001a; Farré and Vella, 2013; van Putten, Dykstra and Schippers, 2008). Characteristics such as education, employment and religious affiliation correlate strongly with the characteristics and social status of parents. At the same time, low levels of education, increased levels of religiousness and a migration background correlate with more traditional gender roles (Davis and Greenstein, 2009). Therefore ideologies are also indirectly passed on from generation to generation through the intergenerational transmission of the social composition.

Although the important role of parents in the intergenerational transmission of gender ideologies is undisputed, the timing and persistence of socialisation effects are not yet fully understood. Parental socialisation effects in mid-adolescence are considered particularly persistent (Cunningham, 2001b), although children are very likely to adapt their attitudes to individual circumstances and later life-course events (Min, Silverstein and Lendon, 2012; Platt and Polavieja, 2016). Some authors have therefore proposed a so-called sleeper effect, according to which certain life events, such as one's career entry or childbirth, activate gender ideologies experienced in childhood (Cunningham, 2001a; Min, Silverstein and Lendon, 2012).

\section{Regime-specific State Socialisation of Gender Ideologies}

Gender ideologies differ considerably between welfare states (Kangas and Rostgaard, 2007; Motiejunaite and Kravchenko, 2008; Sjöberg, 2004), yet most comparative studies only implicitly assume a stable ideology formation in relation to the overall context of parental and welfare state socialisation in childhood. Welfare states presumably influence ideologies in two ways: first, through state institutions and legal frameworks, and second, through intentional or unintentional changes in the social composition of the population (Banaszak, 2006). 
Institutions and policies form the opportunity structures and thus favour certain types of behaviour that may be related to gender-specific roles. According to exposure-based perspectives based on identity theory and social identity theory (Stets and Burke, 2000), individuals construct new images of themselves whenever they experience new roles or a change of social category or group. Changes in role exposure are therefore often accompanied by psychological adaption and a stronger identification with the new role or social category and thus with an altered self-concept (Banaszak, 2006). In this way, opportunity structures promote the formation of gender ideologies that are positively aligned with one's social behaviour.

Family policies appear to be particularly crucial for the formation of gender ideologies as they provide the opportunity structure for reconciling family and work. An extensive literature of cross-national comparisons found family policies to predict variations in gendered behaviour (Boeckmann, Misra and Budig, 2015). But only few comparative studies examine their influence on gender ideologies by using direct measures for family policies (Kangas and Rostgaard, 2007; Motiejunaite and Kravchenko, 2008; Sjöberg, 2004). Some recent evaluation studies on family policy reforms showed moderate changes toward less-traditional gender ideologies for the introduction of parental leave for fathers in Norway (Kotsadam and Finseraas, 2011) and increased childcare capacities in Germany (Zoch and Schober, 2018). However, these studies focused on ideology changes over the life course and did not examine general trends in gender ideologies.

Welfare states are presumed to influence gender ideologies also indirectly by shaping the social composition of society (Banaszak, 2006). By strengthening the importance of, for example, religion, female employment or education through additional financial resources or supportive policies, opportunity structures are created which impact on gender ideologies. Lifecourse events, such as completing an educational degree, the transition to parenthood, or employment transitions, are associated with changes in gender ideologies due to psychological adjustments to altered roles (Baxter et al., 2015; Zoch and Schober, 2018). Interest and 
exposure-based explanations argue that people often support ideologies that are closest to their behaviour or from which they benefit. Thus, highly educated or working women are more likely to have egalitarian views because they are more common in their environment, because their behaviour is consistent with these role conceptions, and because these women benefit more from egalitarian perspectives towards maternal employment and formal childcare themselves (Banaszak, 2006; Bolzendahl and Myers, 2004; Davis and Greenstein, 2009). In this way, the institutional context of welfare states affects individual gender ideologies and differences between population groups.

Although parental socialisation in early childhood and mid-adolescence is considered to be particularly relevant for the formation of attitudes and ideologies, the role of regime-specific state socialisation has not yet been sufficiently investigated. However, the question of whether the institutional context during childhood has a similarly long-lasting influence on gender ideologies compared to parental socialisation effects bears great theoretical importance.

\section{Socialisation Experiences of the Three Cohorts in East and West Germany}

\section{Regime-specific State Socialisation in the FRG and GDR}

The Federal Republic of Germany (FRG) actively supported the marriage-based family with a male breadwinner. In the conservative welfare-regime, marriage was economically crucial due to the free health insurance via the working husband and marriage-related benefits and tax allowances (Leitner, Ostner and Schmitt, 2008). As there was no public childcare for under-threes and hardly any childcare places or after-school care for older children, mothers could only work if they organised childcare privately. Female employment rates were therefore comparatively low and most mothers, if at all, worked part-time after long employment interruptions after child birth (Rosenfeld, Trappe and Gornick, 2004).

Gender equality was also limited before the law. As maternal employment was considered harmful, until the late 1970s, a husband could terminate his wife's employment contract for 
neglect of household duties. Single mothers without a child's father were automatically granted an official guardian and lost comprehensive parental custody (formally until 1998). Abortion without medical necessity was a criminal offence until early 1976. To date, it is still prohibited but not prosecuted under certain conditions. The debate on the abortion law mobilised the women's movement in the FRG particularly strongly, so that the question of general equality was taken up during the late 1970s (Leitner, Ostner and Schmitt, 2008). The FRG thus followed the pattern of other Western societies in which gender roles became somewhat less traditional (Davis and Greenstein, 2009)

In the German Democratic Republic (GDR), supportive work-family policies, gender equality before the law, and propagandised norms of gender equality in the educational system and at work shaped less traditional perspectives on maternal employment and non-parental childcare. Institutions and policies expected full-time employment for both men and women. A comprehensive public childcare system provided care for half of the under-three-year-olds, for almost all children between 3 and 6 years, and, in the form of after-school care and children's camps during the school holidays, also for older children. Children born before the mid-1970s attended childcare frequently and at very early age, as parental leave was not introduced until 1974 and initially only for second and higher-order births. It was only extended to all mothers in 1986 (Drasch, 2013). As a result, the employment rate for women (89\%, 1989) was the highest in the world and comparable to that of men (92\%) (Rosenfeld, Trappe and Gornick, 2004). Thus, in the GDR it was a matter of course for both parents to work and to attend a childcare facility. The image of the working mother was even included in textbooks and children's songs like "Wenn Mutti früh zur Arbeit geht" [When mommy goes to work early].

Likewise, gender equality was established before the law and marriage did not restrict women's rights. The divorce rate was very high despite low alimony obligations, and an illegitimate birth did not lead to restrictions on parental rights (Leitner, Ostner and Schmitt, 
2008). Since 1972, abortions were possible up to 12 weeks without preconditions and contraceptives were available free of charge for every woman.

From the perspective of life-course research, the socialist indoctrination of propagandised norms began early, since children came into close contact with working life already at an early age through the educational system. From grade 7 onwards, they visited factories or farms regularly to perform unpaid, simple manual labour tasks in the production process. ${ }^{1}$ As members in the GDR mass youth movements (Thälmann Pioneers from age 6-14 and Free German youth from age 14), organised by the Socialist Party to bring up young work-oriented socialist, children actively participated in mass parades and demonstrations of workers on public holidays, in the organised collection of waste materials to increase their pocket money or in other, usually unpaid, work assignments, so-called "subbotniks".

As mothers usually worked full-time, children also had to help to a greater extent in the household. Although dual employment led to a moderately more egalitarian division of labour between parents, the division of domestic work and childcare remained strongly gendered also in East Germany (Rosenfeld, Trappe and Gornick, 2004). Since 1952, working mothers and married women were granted a monthly "household day" (source). ${ }^{2}$ As this day off was only granted to men under certain conditions, it institutionalised gendered inequalities in housework. Similarly, additional days off and reduced working hours applied mostly to mothers and not to fathers.

Moreover, the GDR had permanently changed the composition of the East German population until today. Supportive work-family policies and equal access to higher education contributed to an average higher level of education and employment for women compared to West Germany. Conversely, religiosity and church membership were less supported or even sanctioned, for example by denying church members or their children access to higher education. This drastically reduced religiousness. Due to closed borders and separate accommodation of guest workers, natives and foreigners generally remained separate. To this 
day, the proportion of people with a migration background is significantly lower than in West Germany. Previous research has found more traditional gender ideologies especially among homemakers, religious persons and persons with a migrant background (Davis and Greenstein, 2009). The less traditional gender ideologies in East Germany are therefore partly explained by the different composition of the population (Banaszak, 2006; Bauernschuster and Rainer, 2012; Lee, Alwin and Tufis, 2007).

\section{Socialisation in the Post-Reunification Period}

Reunification created one German state with the same laws and institutions practically overnight, so that a convergence of attitudes and ideologies was expected over time. However, many studies remained vague as to whether convergence was also expected for older cohorts born in the GDR or only for younger cohorts born after reunification. With regard to the latter, however, it is doubtful that parental and state socialisation in East and West were suddenly the same. With a different population composition and, in part, still different institutions, life in the East continued to differ in many aspects from life in the West.

After reunification, East German mothers extended their career breaks and part-time rates similar to West German mothers due to increased unemployment and supported by extended parental leave (Drasch, 2013). Hence, East German mothers had more frequent, and longer employment interruptions and more often worked only part-time than before reunification (Leitner, Ostner and Schmitt, 2008). However, supported by higher childcare capacities, mostly provided in full-time, they continued to work more frequently, usually with more hours and still shorter employment breaks, than mothers in West Germany (Rosenfeld, Trappe and Gornick, 2004). Also, East German mothers took on higher shares of household labour, partly because of increased time availability. This made the gender-specific division of gainful employment and domestic work became more traditional than before in the GDR, but still more egalitarian than in the traditional male breadwinner model in the FRG. 
In West Germany, the possibility of gainful employment continued to be limited, and maternal employment rates remained low and female part-time shares high. Only in 1996, a legal entitlement to a childcare place, starting at age four was introduced and led to an expansion of public childcare also in the West (Leitner, Ostner and Schmitt, 2008). Overall, previous studies showed a continuous decline in traditional gender ideologies also for West Germany (Bauernschuster and Rainer, 2012; Lee, Alwin and Tufis, 2007). This is in line with theoretical assumptions on cohort-replacement induced modernisation over time. The debate on the abortion law in the course of reunification and the strong women's movement in the GDR partly supported this development (Leitner, Ostner and Schmitt, 2008). Nevertheless, as women's participation in the labour market and the use of childcare facilities continued to be low in the West, the socialisation of East German children born after reunification remained more egalitarian compared to their West German peers.

\section{Hypotheses}

Under the assumption of long-lasting East-West differences in parental and regime-typical socialisation between the FRG and the GDR (Table A1 in the online supplementary file), it is assumed that East Germans born before reunification still have the least traditional gender ideologies after reunification. But it is also assumed that post-reunification ideologies of East Germans have somewhat adapted to the more traditional institutional framework and ideologies of West Germans after reunification. Thus, East Germans born after reunification are assumed to have more traditional attitudes towards maternal employment (H1a) and the division of housework (H1b) than older East Germans born before the reunification (re-traditionalisation hypothesis). Conversely, following the general trend towards modernisation in all Western countries, West Germans born after reunification are assumed to hold less traditional gender ideologies towards maternal employment $(\mathrm{H} 2 \mathrm{a})$ and the division of housework $(\mathrm{H} 2 \mathrm{~b})$ than West Germans born before the reunification (modernisation hypothesis). 
Due to these opposing ideology tendencies in East and West, East-West differences are likely to have decreased overall. But assuming of long-lasting parental and regime-specific socialisation in the GDR and in view of persistent institutional differences during the 1990s, the younger East Germans are likely to have somewhat less traditional gender ideologies regarding the employment of women than their West Germans peers even after reunification. The ideologies of the younger East and West Germans may therefore not have fully converged. Thus, it is assumed that East-West differences in attitudes towards female employment continue to exist and that these are less pronounced in cohorts born after reunification than in cohorts born before reunification (H3a). Since housework was highly gender-specific in both parts of Germany, East-West difference in attitudes towards housework should generally be less pronounced than attitudes towards female employment. Is it therefore assumed that East-West differences in attitudes towards the division of housework have fully converged among cohorts born after reunification $(\mathrm{H} 3 b)$.

\section{Data and Estimation Strategy}

\section{The German Family Panel pairfam}

The study uses panel data from the first ten waves of the German Family Panel (pairfam) release 10.0 (2008-2018) (Brüderl et al., 2019). The annual survey started in 2008 and offers detailed information on about 12.000 randomly selected anchor respondents of three cohorts (1991-1993, 1981-1983, and 1971-1973) (Huinink et al., 2011). Pairfam is currently the only panel dataset for Germany that regularly surveys items on gender ideologies. All waves that include measures of gender ideologies were used: Wave 1 (2008-2009), wave 3 (2010-2011), wave 5 (2012-2013), wave 7 (2014-2015), wave 9 (2016-2017) and wave 10 (2017-2018).

The sample was restricted to heterosexual respondent repeatedly observed. To make a clear distinction between a socialisation experience in East and West Germany, individuals who moved within the country before or during the observation period were excluded. Thus, two mutually exclusive groups that do not suffer from self-selection were observed. Based on all 
restrictions, the sample consisted of 5,861 West Germans (25,174 observations) and 2,321 East Germans (10,736 observations). Respondents of the 1990s-cohort were observed at the age of 14-27 years (2,939 persons, 12,112 observations), followed by the 1980s-cohort between 2437 years (2,504 persons, 11,133 observations) and the 1970-cohort between $34-47$ years $(2,739$ persons, 12,665 observations). Thus, the three cohorts overlap only slightly in terms of observed age yet (Figure 1). Respondents were interviewed in 4.4 waves on average, with 53 percent of the sample being surveyed in at least 5 of the 6 waves.

$>$ Figure $1<<$

\section{Estimation Strategy}

The empirical analyses followed a two-step procedure. First, by using cohort-specific random-effects growth curve models for men and women with clustered standard errors, descriptive means of attitudes for the three different cohorts in East and West Germany were analysed across age. Second, a two-fold Oaxaca-Blinder counterfactual decomposition (Oaxaca, 1973; Jann, 2008) was applied to investigate mean attitude differences between East and West in greater detail. This method divides the attitudinal differential into a first part that is explained by compositional differences of the two groups (explained part/endowment or composition effect). In other words, it investigates the size of the part of the East-West gap in gender ideologies that can be attributed to East-West differences in characteristics that are relevant for gender ideologies. A second part subsumes the observed differences due to unobserved predictors (unexplained part). This part attributes the remaining part of the gap to differences in attitude formation, i.e. how the formation of attitudes is linked to the observed as well as unobserved characteristics. The decomposition is reported from the viewpoint of East Germans, so the coefficients of West German respondents are used as the reference coefficients. The explained part therefore illustrates how the attitude distribution in the group of East Germans would look like if it had the same distribution of determinants as the group of West Germans. The unexplained part illustrates how the attitude distribution of East Germans would 
change if we would apply the observed coefficients of West Germans to the characteristics of the East German sample.

Dependent variables. The analyses focused on three attitudinal items: "Women should be more concerned about family than about career" (referred to as: Female Employment),"Men should participate in housework to the same extent as women" (Housework), "A child under age 6 will suffer from having a working mother" (Maternal Employment) The response scale ranged from 1 (strongly disagree) to 5 (strongly agree), and as the egalitarian phrased item on housework was recoded, higher values represented more traditional gender ideologies for all items (Table A1). Although an explanatory factor analysis suggested one factor, Cronbach's alpha was rather low for all subsamples (.46 to .54). As agreement on individual dimensions does not have to coincide and attitudes can develop in different directions, i.e. less traditional attitudes towards one dimension, are not automatically accompanied by less traditional attitudes towards another dimension, an index would blur possible differences and diverging trends in ideologies. Hence, all items were analysed separately, which corresponds to the theoretical discussion of the conceptually distinct dimensions of gender ideologies (Knight and Brinton, 2017). The three items reflect the division of domestic work in the private sphere (Housework), gender equalities in the labour market (FemEmpl) and the intersection of the two spheres in the form of maternal employment (MatEmpl).

Independent variables. The cohort-specific random-effects growth curve models with full controls and the Oaxaca-Blinder counterfactual include the following individual-level control variables: age (centred for each cohort), gender, education, migration background, religiosity, family and employment status. On the household-level models account for differences in household income $(\log )$, the number of children, the age of the youngest child, a new-born child, a current pregnancy, childcare take-up and partners' employment status. To further avoid the age-period-cohort problem, rather than including year dummies, all models control for potential period effects by including the unemployment and childcare take-up rate on the federal 
level directly. Lastly, all models control for the gender of the interviewer as previous research highlights more egalitarian attitudes to female interviewers (Zoch, 2019) (Table A2 in the online supplementary file).

\section{Findings}

\section{Descriptives}

Table 1 shows the average agreement with the three dimensions of gender ideologies of the three cohorts in East and West Germany. East Germans showed lower values, i.e. less traditional gender role attitudes, than West Germans for all items. In accordance with the modernization hypothesis, youngest West Germans showed the least traditional attitudes regarding female employment (FemEmpl) and the division of domestic work (Housework). In contrast, attitudes towards maternal employment were more traditional (MatEmpl). In East Germany, attitudes towards MatEmpl were more traditional for the youngest cohort, confirming the re-traditionalisation hypothesis. Conversely, attitudes towards FemEmpl and Housework differed only slightly between the three East German cohorts.

Furthermore, East and West Germans differed considerably in their characteristics (Table A2 in the online supplementary file). East-West differences were greater for the two older cohorts and particularly striking for religion, migration background, education and employment. Most East Germans had no denomination and more than 60 percent never attended church, so that the proportion of non-religious people was more than twice as high as in West Germany. Similarly, a quarter of all West German had a migration background, while the proportion of East Germans was only 7 to 12 percent. Educational attainment and employment participation differed only slightly between the youngest cohorts. In the 1970s- and 1980scohorts, however, more East Germans had completed vocational training, while more West Germans had a university degree. In contrast, part-time employment was higher in the older West Germans cohorts, while more East Germans were in full-time employment, reflecting the 
different employment participation of women. East Germans born before the reunification lived together more often, had children and made use of non-parental childcare than West Germans. The youngest child was on average older than in the West, indicating that family formation started earlier in the East. Conversely, the transition to parenthood did not yet seem to play a role for the younger cohort. Finally, the higher unemployment and childcare rates in the East German Federal States showed persistent differences in the institutional context. Overall, the descriptive results suggested that observed East-West differences in gender ideologies may be partly due to differences in composition, especially among the older cohorts, and to age effects correlated with employment participation and family formation.

$>>$ Table $1<<$

\section{Cohort-Differences in Gender Ideologies in East and West Germany}

Baseline cohort-specific random effects growth curve models in Table 2 (M1) confirmed the descriptive findings above with lower mean attitude scores for East Germans across all items and cohorts at their cohort-specific mean-centred age (full models in Table A3-A5 in the Online Appendix). All east coefficients were statistically significant at least at the 5 percent level, and effects sizes corresponded to 10 (Housework) to 50 percent (MatEmpl) of the standard deviation for the respective item and cohort. East-West differences were particularly pronounced for FemEmpl (-.12 to -.22) and MatEmpl (-.43 to -.71). As expected, for all items East-West differences were smaller for the 1990s-cohort (-.12 to -.43) compared to the oldest 1970s-cohorts (-.16 to -.71). Hence, the results provided tentative evidence for the Hypothesis H3 that East-West differences in attitudes are less pronounced for cohorts born after reunification than for those born before reunification.

$>>$ Table $2<<$

To ensure that the East-West differences observed at the cohort-specific mean-centred age did not change with age and, thus, level out differences, Figure 2 illustrates the attitudinal differences across age based on the empty cohort-specific growth-curve models. In line with 
the theoretical assumptions, the graphical presentation confirmed persistent East-West disparities in attitudes, with larger differences for FemEmpl and MatEmpl in the older cohorts and smaller gaps for Housework in all cohorts.

Furthermore, the results pointed to small changes in attitudes over the life-course within cohorts in East and West, which slightly modified the East-West differences during the observation period. For FemEmpl, changes were small and overall ambiguous. While attitudes became less traditional for the youngest cohorts in East and West as well as the oldest West German cohort, the 1980s-cohort experienced a shift towards more traditional attitudes. Thus, the East-West disparities remained largely stable. Conversely, attitudes towards Housework converged strongly. Both East and West Germans in the two older cohorts experienced slightly more traditional attitudes with age. However, in line with re-traditionalisation assumptions it was East Germans who became more traditional over age and thus more similar to West Germans. Only the convergence in the youngest cohort seemed to be driven by more egalitarian attitudes among West Germans. Lastly, attitudes towards MatEmpl changed most within ten years of observation. Surprisingly, respondents in East and West both became less traditional, especially in the 1990s-cohort and West Germany. The East-West differences therefore decreased substantially. Nevertheless, the gaps remained large and statistically significant. For the 1970s-cohort, attitudes remained mostly stable.

In sum, the result showed that the change in East-West differences in gender ideologies was not only due to cohort-based changes, but also driven by small attitudinal changes over the life course within cohorts.

$>$ Figure $2<<$

With individual, household and regional controls, the East coefficients in the random effects growth curve models were reduced and became statistically insignificant for the items FemEmpl and Housework (Table 2, M2; full models in Tables A3-A5 and Figure A1 Online). For the 1980s-cohort, attitudinal difference even reversed. The effect sizes of the controls were 
small and in line with theoretical considerations and previous results from other related studies. The results imply that compositional differences between East and West Germany explained most of the observed attitudinal differences. For MatEmpl, however, East-West differences were reduced but remained substantial for all cohorts, with more pronounced and statistically significant differences for the two older cohorts.

Overall, the results of the random-effects growth curve models support the hypotheses that East-West differences in attitudes towards the division of housework no longer exist in younger cohorts (H3b). Differences regarding women's employment have decreased but still exist, however, only with respect to maternal employment and not female employment (H3a).

\section{Decomposing East-West differences in Gender Ideologies}

The decreased East-West differences could not only be related to changes in composition but also changes in the group-specific formation of attitudes. Table 3 presents results for cohortspecific counterfactual Oaxaca-Blinder twofold decompositions of the East-West differences in attitudes for the three cohorts. The estimated group-specific mean attitudes confirmed the findings of the random-effects growth curve models, with more traditional ideologies for West Germany across all items and cohorts. Again, East-West differences were more pronounced and statistically significant for FemEmpl and MatEmpl, particularly for the oldest cohort.

The decomposition revealed that East Germans of all cohorts would have more traditional attitudes if they had the same distribution of determinants as West German respondents. However, attitude gaps were only partly related to compositional differences in the determinants (explained part) but mainly to East-West differences in the formation of attitudes based on these determinants (unexplained part). Although the relative contributions of compositional and behavioural factors to the observed attitudinal differences varied across items and cohorts (detailed composition in Table A6 in the Online Appendix), behavioural factors explained larger shares of the attitudinal gap for all items (44 to 94 percent). The results 
thus partially support the assumption that differences in composition explain differences in attitudes but highlight the role of differences in the formation of attitudes based on similar observed and unobserved characteristics.

$>$ Table $3<<$

\section{Decomposing East-West differences in gender ideologies across cohorts of similar age}

The different cohorts overlapped only partially in terms of observed age so that compositional differences were likely to result from age-related living conditions. To reduce age-specific differences between the three cohorts, they were again compared in pairs when observed at a similar age. Precisely, the oldest 1970s-cohort (observed 2008 to 2011) was compared with the 1980s-cohort (observed 2015 to 2018) when individuals were aged 34 to 37 years. Similarly, the youngest 1990s-cohort (observed 2015 to 2018) was compared with the middle 1980s-cohort observed 2008 to 2011) when respondents were between 24 and 27 years.

When turning to the results from the age-specific counterfactual Oaxaca-Blinder twofold decomposition in Table 4 (detailed composition in Table A7 in the Online Appendix), it again becomes evident that average attitudes vary considerably between cohorts. Comparing the two oldest cohorts aged 34 to 37 (M3 and M4) confirmed again decreasing East-West differences in employment-related attitudes due to cohort-replacement based modernization of West Germans and partial re-traditionalization of East Germans. West Germans showed particularly marked changes towards less traditional attitudes (FemEmpl: 2.82-3= -0.18; MatEmpl: 3.173.32=-0.15). The 1980s-cohort in East Germany showed more traditional attitudes towards FemEmpl than the older cohort (+.27), but comparatively stable attitude towards MatEmpl (.02). Contrary to theoretical expectations, however, attitudes towards Housework became more traditional not only in the East (+.53) but also in the West (+.12), which further widened the gap. In view of particularly significant changes in the East, East-West difference even reversed.

Surprisingly, the comparison of the 1990s- and 1980s-cohorts at age 24 to 27 (M1 and M2) showed less traditional attitudes towards FemEmpl and MatEmpl for the younger cohort in both 
East and West. Despite similar trends, but due to different degrees of modernisation with more substantial changes in the East (-.38) than in the West (-.10), East-West disparities in attitudes to FemEmpl did not decrease but instead widened. Similar, the gap in attitudes towards MatEmpl widened due to a stronger modernization in West (-.37) compared to East Germany (-.17). While the modernized attitudes in West Germany are in line with theoretical expectations, results for East Germany therefore contradict the presumed re-traditionalisation. Moreover, attitudes towards Housework became more traditional in West Germany (+.17) and less traditional in East Germany (-.21), so that the East-West differences for the 1990s-cohort widened again in this respect as well and, thus, also contradict the theoretical expectations for the youngest cohort.

The decomposition results for the comparison of the three cohorts at similar age confirmed again that East Germans would have more traditional attitudes if they had the same distribution of determinants as the West German respondents. The relative contribution of the compositional differences to the attitude gap was, however, more substantial for the 1980s- and 1970s-cohort but statistically significant only for some of the models on FemEmpl and MatEmpl. Conversely, the contribution of behavioural factors to the attitude differences was again particularly pronounced and statistically significant for the youngest cohort. Hence, the results suggest that differences in the composition of the population explain the East-West differences in attitudes to different degrees for the individual cohorts. Moreover, the type of attitudinal formation that was associated with the characteristics of the respective cohort seemed to have changed over time.

$>>$ Table $4<<$

\section{Sensitivity Checks}

Several sensitivity checks were conducted that reinforce the presented findings (results included in Online Appendix). To ensure that results were not driven by selective panel attrition, all models were re-estimated for respondents, observed in all six waves. Results from cohort- 
specific random effects growth curve models and Oaxaca-Blinder decomposition showed similar patterns for the smaller samples and therefore confirmed the findings (Figure A2, Tables A8 to A12). Moreover, information on how many years the mother was employed before the respondent's 6th birthday as well as mother's current attitude towards the examined attitude item was included in all models to control for articulated attitudes and behavioural aspects of parental socialisation in early childhood. Unfortunately, this information was only available for fifty percent of the sample (Table A13). The attitudes of the respondents correlated strongly with the attitudes of their mothers and her employment during respondents' childhood, and showed the expected cohort-specific patterns in East and West Germany. However, the additional controls explained the remaining East-West differences only with respect to MatEmpl and, as expected, particularly for the two older cohorts (Figures A3 and A4; Tables A14-A16). The results therefore confirm the assumption of regime-specific differences in behaviour modelling and the intergenerational transmission of gender ideologies.

Given substantial gender differences in gender ideologies in previous research, the cohortspecific random-effects growth curve models were re-estimated separately for men and women. Across all cohorts, East-West differences in attitudes towards MatEmpl were more substantial for men than for women. Conversely, East-West differences for Housework were only relevant for women in the 1980s-cohort (Figure A5).To further investigate relevant gender differences within East and West, cohort-specific random-random effects growth curves models with an interaction for gender were estimated separately for East and West. For FemEmpl, gender differences in East and West were small and statistically mostly insignificant. For the two other items, results, however, confirmed persistently less traditional attitudes among East and West German women compared to men (Figure A6). In West Germany, gender differences in attitudes towards MatEmpl were particularly pronounced in all three cohorts and even increased during the observation period. 


\section{Summary and Discussion}

This study provides new insights into the formation and cohort-specific changes in gender ideologies in the context of Germany. By extending the focus to younger cohorts, born shortly before and after the reunification of Germany, it is the first study to examine East-West differences in gender ideologies based on panel data. With its historical regime change, Germany offers the unique opportunity to investigate how different political regimes and opportunity structures in East and West Germany affect the formation of gender ideologies, how persistent these regime influences are and which factors explain possible changes in ideologies over time. During the division of Germany, the two states influenced gender ideologies quite differently through their policies and their effects on the composition of the population. By exploiting differences in regime-specific socialisation for three cohorts born in the early 1970s, 1980s, and 1990s in East and West Germany, the study finds persistent EastWest differences in gender ideologies even 30 years after reunification. However, as expected, East-West differences in gender ideologies varied between cohorts and for the individual dimension of gender role attitudes.

Overall, the findings suggest smaller attitudinal gaps among the post-reunification cohort compared to more substantial and persistent East-West differences among respondents that were born in the two separate German parts. Gender ideologies seem to have converged partly over cohorts due to modernisation trends in West Germany and some re-traditionalisation effects in East Germany. The convergence seems to be more pronounced for attitudes towards housework and female employment and when comparing respondents from the 1970s- and 1980s-cohort. In contrast, and although the gap has narrowed, attitudinal differences towards maternal employment and the consequences for children's well-being remain persistent. Surprisingly, the youngest East Germans showed no further re-traditionalization but again more egalitarian attitudes towards all items compared to the 1980s-cohort and their West German peers. The results, therefore, confirm that the institutional framework in East and West before 
and after the division of Germany is linked to cohort-specific socialisation experiences and suggest that the regime-specific socialisation experiences of parents are passed on to younger generations as part of the intergenerational transmission of ideologies.

Overall, the results support the assumption that the different gender ideologies in East and West Germany would converge after reunification and partly contradict earlier findings on increased East-West differences in gender ideologies among older cohorts (Banaszak, 2006; Bauernschuster and Rainer, 2012; Lee, Alwin and Tufis, 2007). The somewhat increased EastWest differences among the youngest cohort partly result from different trends in modernization. However, this youngest cohort has not been confronted with gendered institutions and a re-traditionalisation of attitudes, related to family formation and associated employment transitions, particularly among women. It therefore open, whether East-West specific reconciled attitudes will further alter ideology differences or if the more supportive work-family policies recently introduced, will enable this generation to align their less traditional attitudes with individual work-care decisions and, thus, prevent a retraditionalisation due to the transition to parenthood.

Overall, East Germans of all cohorts would have had more traditional gender ideologies if they had the same distribution of determinants as West German respondents. Beyond this, the findings show that only small parts of the attitude gaps are explained by differences in the observed composition of the East and West German subsamples, particularly for the youngest cohort. Instead, large parts of the attitudinal gap seem to be related to differences in attitude formation associated with individual characteristics and life-course events. The characteristics seem to have changed in their influence on the formation of attitudes, so that, for example, maternal employment today is not as closely linked to very egalitarian attitudes as it was 20 years ago. Together with the descriptive findings, the results show that the composition in the two parts of Germany has somewhat narrowed, for example, concerning educational attainment and maternal employment participation. Moreover, some of the observed differences are most 
likely due to age effects, with family formation not yet have been completed in the middle cohort and many critical family events still pending for the youngest cohort. The relevance of compositional differences might, therefore, increase again in future years.

Moreover, the results highlight the relevance of attitudinal changes over the life-course in East and West, slightly modifying the East-West disparities over the observation period. All cohorts in East and West showed more traditional attitudes towards the division of housework with increased age, with more pronounced changes among the two older cohorts and in East Germany. The results are in line with previous findings on re-traditionalisation processes across age after the transition to parenthood (Nitsche and Grunow, 2016). Conversely, all cohorts in East and West became more egalitarian regarding the consequences of maternal employment for early child development, with particularly pronounced changes in West Germany and among the two younger cohorts. These changes are most likely associated with the tremendous increase in public childcare for under-threes and associated changes in work-care norms (Zoch and Schober, 2018). For attitudes towards female employment, changes were comparatively small and more ambiguous. Hence, in sum the results expand upon previous cross-sectional studies that were unable to acknowledge both sources of attitudinal changes for the contribution to changes in the overall trends of gender ideologies (Banaszak, 2006; Bauernschuster and Rainer, 2012; Lee, Alwin and Tufis, 2007). From a broader perspective, the results are also in line with previous arguments on the competing ideals regarding gender roles for the market place and family life (Knight and Brinton, 2017). In both East and West Germany, the attitudelevel, the attitudinal changes and, thus, the East-West differences varied for the examined dimensions.

A major limitation of the study is the small overlap of the three cohorts in terms of observed age, which did not allow to estimate joint models for the three cohorts in order to precisely analyse and separate age and cohort effects. While the cohort-specific random effects growth curve models indicate persistent East-West differences in gender ideologies, the risk of biased 
estimates remains due to unobserved characteristics that are likely to correlate with cohortspecific socialisation and gender ideologies. ${ }^{3}$ Similar, although institutional changes over the observation period are likely to matter, an age-period specification is, however, unfortunately not identified. Hence, overall results most likely do not identify a causal link and should, therefore, be interpreted with caution. Future research should investigate the reasons for the observed attitude changes across and within cohorts more thoroughly by applying a withinestimate of the age-effect to a suitable panel database. However, since the pairfam data currently constitutes the best database for Germany, the present study nevertheless makes a decisive contribution and supplements the previous cross-sectional studies on East-West differences in gender ideologies, while at the same time, extending the focus to younger cohorts with the help of panel data.

Overall, this study provides evidence for both the regime-specific socialisation effect but also for a slow convergence of gender ideologies after reunification. The study suggests that convergence is not only driven by cohort replacement-based convergence but also small attitudinal adaptation over the life-course, which is evident even for older cohorts, born twenty years before reunification. Hence, the findings emphasise the importance of persistent, longlasting ideology differences due to the regime-specific socialisation and compositional differences during the former division. At the same time, it challenges previous assumptions on stable attitudes after early socialisation but points towards the importance of alterable gender ideologies over the life-course for the contribution to changes to overall trends of gender ideologies. Future research should further focus on the ideology formation of younger cohorts at early age, to fully understand the underlying mechanisms of the intergenerational transmission and cohort-based replacement of gender ideologies. 
1 The subject was called Productive Work (PA) and, together with the subjects "Introduction to Socialist Production" (ESP) and "Technical Drawing" (TC), part of the practical component of the training at the most widespread ten-year tracks at the polytechnic schools.

${ }^{2}$ In 1965, the "Haushaltstag" was extended first to unmarried mothers with a child under 18 years of age and in 1977 to unmarried and childless women over 40 years of age.

${ }^{3}$ Similar, estimating cohort differences in attitude trajectories using a joint fixed-effects model for all cohorts, would result in group differences that are not interpretable due to the restriction of an equal starting attitude value at age zero. Accordingly, cohort-specific FE-regressions do not provide a well-defined alternative. 


\section{References}

Adler, M. A. and Brayfield, A. (1997). Women's Work Values in Unified Germany: Regional Differences as Remnants of the Past. Work and Occupations, 24, 245-266.

Banaszak, L. A. (2006). The Gendering State and Citizens' Attitudes toward Women's Roles. State Policy, Employment, and Religion in Germany. Politics \& Gender, 2, 29-55.

Bauernschuster, S. and Rainer, H. (2012). Political regimes and the family: how sex-role attitudes continue to differ in reunified Germany. Journal of Population Economics, 25, 5-27.

Baxter, J., Buchler, S., Perales, F. and Western, M. (2015). A Life-Changing Event: First Births and Men's and Women's Attitudes to Mothering and Gender Divisions of Labor. Social Forces, 93, 989-1014.

Boeckmann, I., Misra, J. and Budig, M. J. (2015). Cultural and Institutional Factors Shaping Mothers' Employment and Working Hours in Postindustrial Countries. Social Forces, 93, 1301-1333.

Bolzendahl, C. I. and Myers, D. J. (2004). Feminist Attitudes and Support for Gender Equality. Opinion Change in Women and Men, 1974-1998. Social Forces, 83, 759-789.

Braun, M., Scott, J. and Alwin, D. F. (1994). Economic necessity or self-actualization? Attitudes toward women's labour-force participation in East and West Germany. European Sociological Review, 10, 29-47.

Brooks, C. and Bolzendahl, C. (2004). The transformation of US gender role attitudes: cohort replacement, social-structural change, and ideological learning. Social Science Research, 33, 106133.

Brüderl, J., Drobnič, S., Hank, K., Nauck, B., Neyer, F. J., Walper, S., Alt, P., Bozoyan, C., Buhr, P., Finn, C., Garrett, M., Greischel, H., Gröpler, N., Hajek, K., Herzig, M., Huyer-May, B., Lenke, R., Minkus, L., Müller, B., Peter, T., Schmiedeberg, C., Schütze, P., Schumann, N., Thönnissen, C., Wetzel, M. and Wilhelm, B. (2019). Beziehungs- und Familienpanel (pairfam): GESIS Data Archive.

Cordero-Coma, J. and Esping-Andersen, G. (2018). The Intergenerational Transmission of Gender Roles: Children's Contribution to Housework in Germany. Journal of Marriage and Family, 80, 1005-1019.

Cunningham, M. (2001a). Parental influences on the gendered division of housework. American Sociological Review, 66, 184-203.

Cunningham, M. (2001b). The Influence of Parental Attitudes and Behaviors on Children's Attitudes Toward Gender and Household Labor in Early Adulthood. Journal of Marriage and Family, 63, 111-122.

Davis, S. N. and Greenstein, T. N. (2009). Gender Ideology: Components, Predictors, and Consequences. Annual Review of Sociology, 35, 87-105.

Drasch, K. (2013). The re-entry of mothers in Germany into employment after family-related interruptions. Empirical evidence and methodological aspects from a life course perspective. Bielefeld: Bertelsmann.

Farré, L. and Vella, F. (2013). The Intergenerational Transmission of Gender Role Attitudes and its Implications for Female Labour Force Participation. Economica, 80, 219-247.

Huinink, J., Brüderl, J., Nauck, B., Walper, S., Castiglioni, L. and Feldhaus, M. (2011). Panel Analysis of Intimate Relationships and Family Dynamics (pairfam): Conceptual framework and design. Panel Analysis of Intimate Relationships and Family Dynamics (pairfam): konzeptioneller Rahmen und Forschungsdesign. Zeitschrift für Familienforschung, 23, 77-101.

Jann, B. (2008). The Blinder-Oaxaca Decomposition for Linear Regression Models. The Stata Journal: Promoting communications on statistics and Stata, 8, 453-479.

Kangas, O. and Rostgaard, T. (2007). Preferences or institutions? Work-family life opportunities in seven European countries. Journal of European Social Policy, 17, 240-256.

Knight, C. R. and Brinton, M. C. (2017). One Egalitarianism or Several? Two Decades of Gender-Role Attitude Change in Europe. American Journal of Sociology, 122, 1485-1532.

Kotsadam, A. and Finseraas, H. (2011). The state intervenes in the battle of the sexes: Causal effects of paternity leave. Social Science Research, 40, 1611-1622. 
Lee, K. S., Alwin, D. F. and Tufis, P. A. (2007). Beliefs about women's labour in the reunified Germany, 1991-2004. European Sociological Review, 23, 487-503.

Leitner, S., Ostner, I. and Schmitt, C. (2008). Family Policies in Germany. In Ostner, I. and Schmitt, C. (Eds.). Family Policies in the Context of Family Change. s.I.: VS Verlag für Sozialwissenschaften (GWV), pp. 175-202.

Min, J., Silverstein, M. and Lendon, J. P. (2012). Intergenerational transmission of values over the family life course. Advances in Life Course Research, 17, 112-120.

Motiejunaite, A. and Kravchenko, Z. (2008). Family policy, employment and gender-role attitudes: a comparative analysis of Russia and Sweden. Journal of European Social Policy, 18, 38-49.

Nitsche, N. and Grunow, D. (2016). Housework over the course of relationships: Gender ideology, resources, and the division of housework from a growth curve perspective. Advances in Life Course Research, 29, 80-94.

Oaxaca, R. (1973). Male-Female Wage Differentials in Urban Labor Markets. International Economic Review, 14, 693-709.

Platt, L. and Polavieja, J. (2016). Saying and Doing Gender: Intergenerational Transmission of Attitudes towards the Sexual Division of Labour. European Sociological Review, 32, 820-834.

Rosenfeld, R. A., Trappe, H. and Gornick, J. C. (2004). Gender and Work in Germany. Before and After Reunification. Annual Review of Sociology, 30, 103-124.

Sjöberg, O. (2004). The Role of Family Policy Institutions in Explaining Gender-Role Attitudes: A Comparative Multilevel Analysis of Thirteen Industrialized Countries. Journal of European Social Policy, 14, 107-123.

Stets, J. E. and Burke, P. J. (2000). Identity Theory and Social Identity Theory. Social Psychology Quarterly, 63, 224-237.

van Putten, A. E., Dykstra, P. A. and Schippers, J. J. (2008). Just Like Mom? The Intergenerational Reproduction of Women's Paid Work. European Sociological Review, 24, 435-449.

Zoch, G. (2019). Gender-of-interviewer Effects in Self-reported Gender Ideologies - Evidence Based on Interviewer Change in a Panel Survey. Working Paper.

Zoch, G. and Schober, P. S. (2018). Public Child-Care Expansion and Changing Gender Ideologies of Parents in Germany. Journal of Marriage and Family, 80, 1020-1039. 


\section{Figures and Tables}

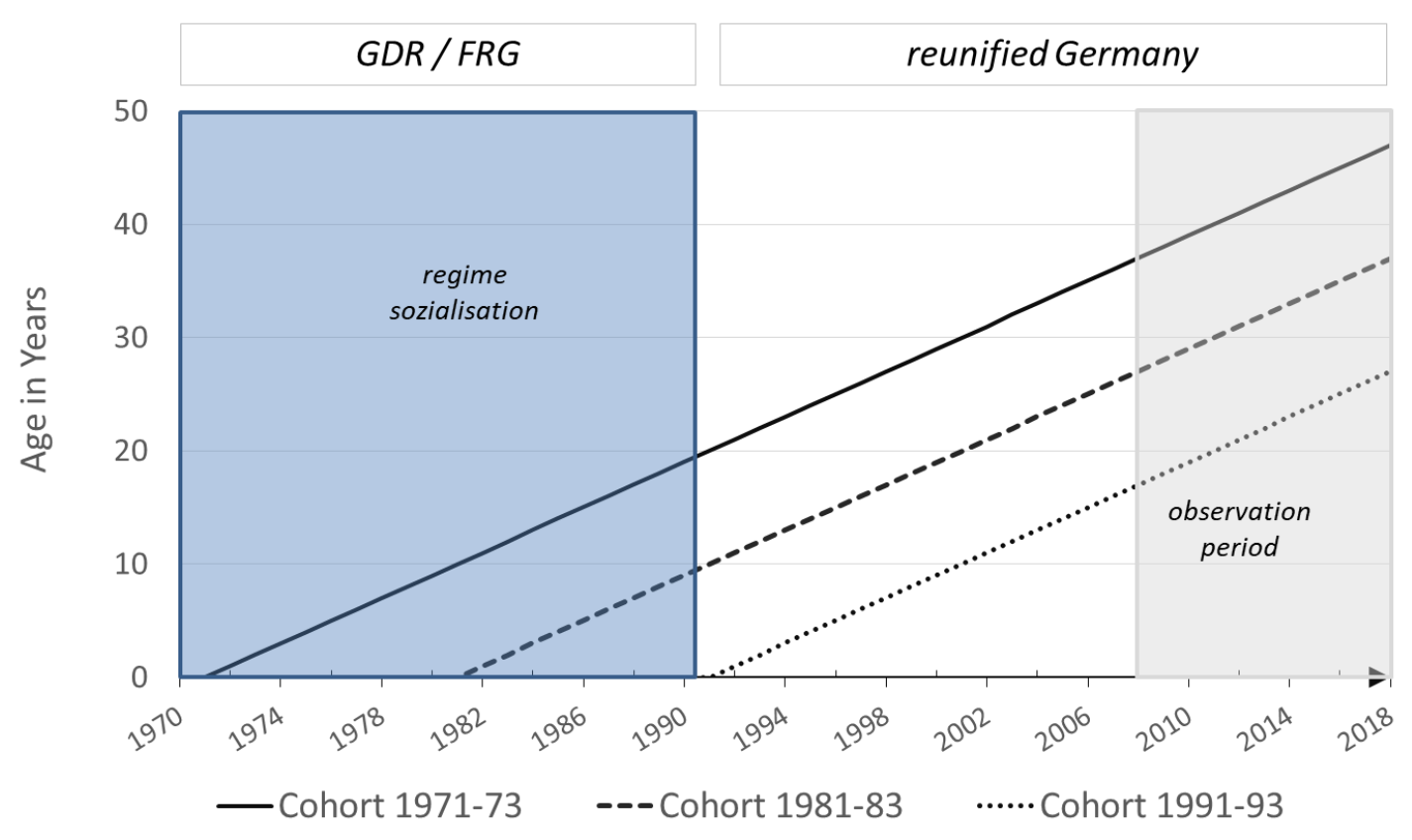

Figure 1. Overview of the Period of Separate Regime Socialisation and of the Observation Period of the Three Cohorts in East and West. 


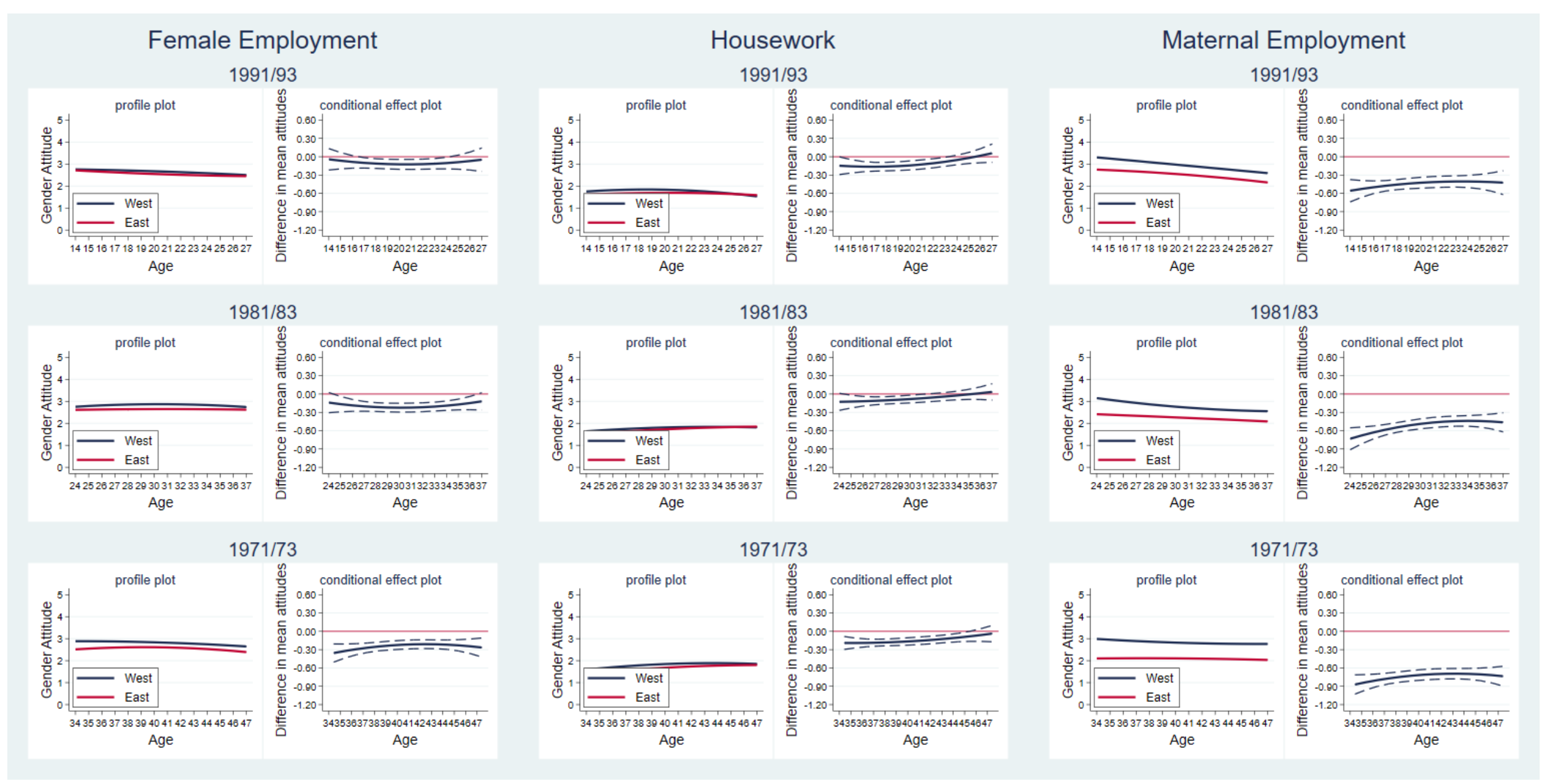

Figure 2. Cohort-specific Random Effects Growth Curve Models for Average Mean Differences in Gender Ideologies between East and West (Base Models).

Note: Profile plots (left) and effect plots (right) estimated by cohort-specific random-effects growth-curve-models. No control variables. $\mathrm{N}_{\text {Cohort-1990 }}=12,112 ; \mathrm{N}_{\text {Cohort- }}$ ${ }_{1980}=11,133 ; \mathrm{N}_{\text {Cohort }-1970}=12,665$. See Table 1 and Tables A3-A6 for detailed regression results. Source: pairfam $10.0(2008-2018)$. 
Table 1. Mean Gender Role Attitudes for West and East German Cohorts.

\begin{tabular}{|c|c|c|c|c|c|c|c|c|c|c|c|c|}
\hline \multirow[b]{4}{*}{ Gender role attitude - item } & \multicolumn{6}{|c|}{ West Germany } & \multicolumn{6}{|c|}{ East Germany } \\
\hline & \multicolumn{4}{|c|}{ Cohort } & \multirow{2}{*}{\multicolumn{2}{|c|}{ 1971-73 }} & \multicolumn{6}{|c|}{ Cohort } \\
\hline & \multicolumn{2}{|c|}{ 1991-93 } & \multicolumn{2}{|c|}{ 1981-83 } & & & \multicolumn{2}{|c|}{$1991-93$} & \multicolumn{2}{|c|}{ 1981-83 } & \multicolumn{2}{|c|}{ 1971-73 } \\
\hline & mean & $\mathrm{SD}$ & mean & $\mathrm{SD}$ & mean & $\mathrm{SD}$ & mean & SD & mean & SD & mean & SD \\
\hline $\begin{array}{l}\text { FemEmpl: "Women should be more concerned } \\
\text { about family than about career." }\end{array}$ & 2.64 & 1.01 & 2.83 & 1.07 & 2.78 & 1.08 & 2.57 & 1.01 & 2.64 & 1.02 & 2.55 & 1.07 \\
\hline $\begin{array}{l}\text { Housework: "Men should participate in housewor } \\
\text { to the same extent as women" (reversed) }\end{array}$ & 1.78 & 0.90 & 1.79 & 0.90 & 1.81 & 0.91 & 1.65 & 0.86 & 1.72 & 0.89 & 1.66 & 0.86 \\
\hline $\begin{array}{l}\text { MatEmpl: "A child under age } 6 \text { will suffer from } \\
\text { having a working mother" }\end{array}$ & 2.96 & 1.13 & 2.76 & 1.20 & 2.79 & 1.31 & 2.53 & 1.07 & 2.24 & 1.13 & 2.07 & 1.17 \\
\hline Cronbach's alpha & & & 0 . & & & & & & & & & \\
\hline Observations & & & 69 & & & & & & & & & \\
\hline Unique individuals & & & 15 & & & & & & & & & \\
\hline
\end{tabular}

Note: Response scale: 1 (strongly disagree) to 5 (strongly agree). For all items, higher values indicate more traditional gender ideologies. East-West

differences significant for all items and cohorts (t-test, $\mathrm{p}=0.05)$.

Source: pairfam 10.0 (2008-2018). 
Table 2. Cohort-specific Random Effects Growth Curve Models for Average Mean Differences between East and West (Base and Full Models).

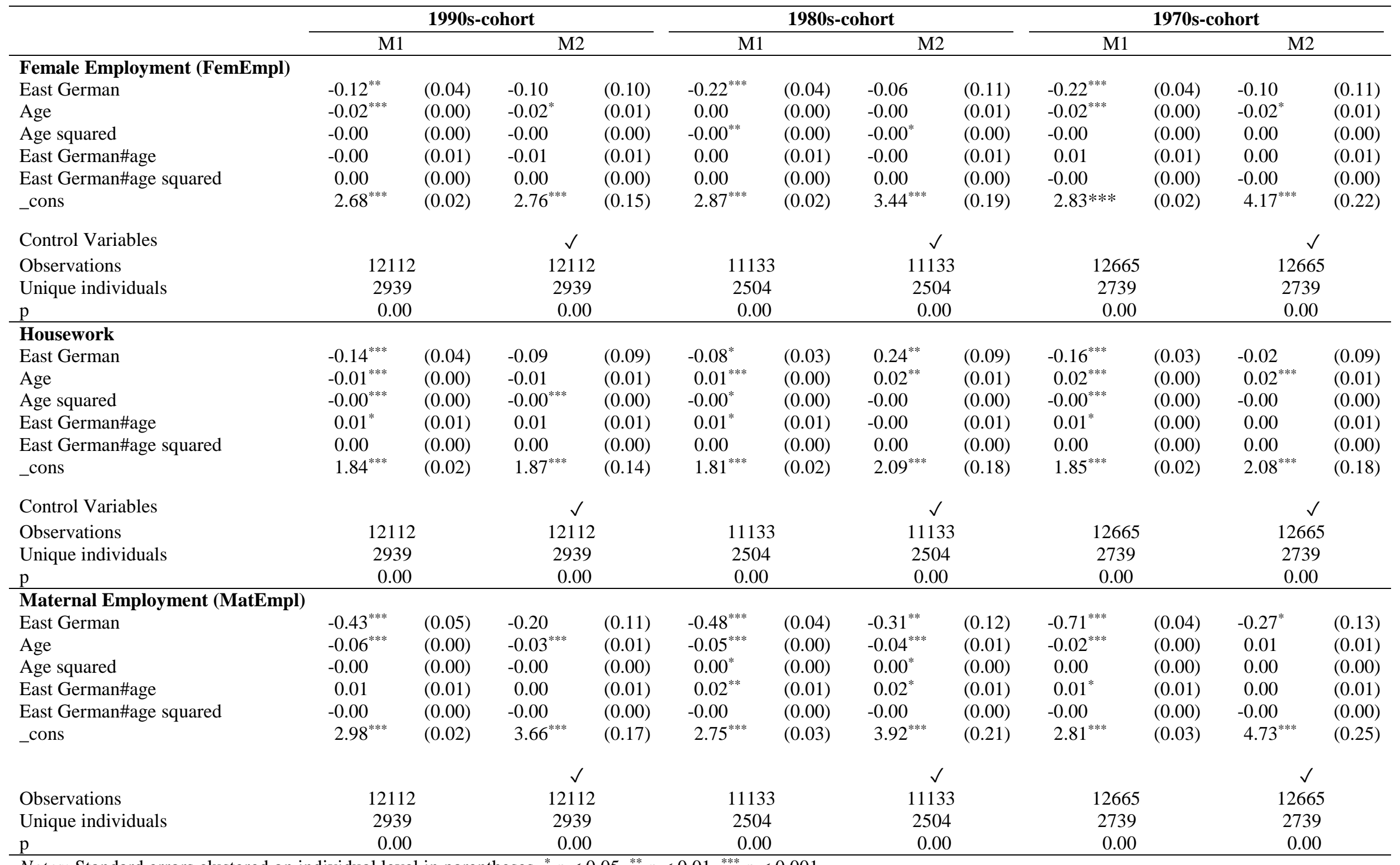

Notes: Standard errors clustered on individual level in parentheses. ${ }^{*} p<0.05,{ }^{* *} p<0.01,{ }^{* * * *} p<0.001$

Source: pairfam 10.0 (2008-2018). 
Table 3. Oaxaca-Blinder Twofold Decomposition Results for the Predicted East-West Differences in Gender Ideologies: Comparing the three Cohorts.

\begin{tabular}{|c|c|c|c|c|c|c|c|c|c|}
\hline & \multicolumn{3}{|c|}{ FemEmpl } & \multicolumn{3}{|c|}{ Housework } & \multicolumn{3}{|c|}{ MatEmpl } \\
\hline & 1990s & 1980s & 1970s & 1990s & 1980s & 1970s & 1990s & 1980s & 1970s \\
\hline & M1 & M2 & M3 & M4 & M5 & M6 & M7 & M8 & M9 \\
\hline $\begin{array}{l}\text { Differential } \\
\text { West Germany }\end{array}$ & $\begin{array}{l}2.63^{* * *} \\
(0.05)\end{array}$ & $\begin{array}{l}2.91^{* * *} \\
(0.05)\end{array}$ & $\begin{array}{l}3.00^{* * *} \\
(0.06)\end{array}$ & $\begin{array}{l}1.80^{\text {**** }} \\
(0.04)\end{array}$ & $\begin{array}{l}1.77^{\text {*** }} \\
(0.05)\end{array}$ & $\begin{array}{l}1.70^{* * * *} \\
(0.05)\end{array}$ & $\begin{array}{l}2.94^{* * *} \\
(0.06)\end{array}$ & $\begin{array}{l}3.00^{* * *} \\
(0.06)\end{array}$ & $\begin{array}{l}3.17^{* * *} \\
(0.08)\end{array}$ \\
\hline East Germany & $\begin{array}{l}2.49^{* * * *} \\
(0.07)\end{array}$ & $\begin{array}{l}2.69^{* * *} \\
(0.07)\end{array}$ & $\begin{array}{l}2.57^{* * *} \\
(0.08)\end{array}$ & $\begin{array}{l}1.55^{\text {*** }} \\
(0.05)\end{array}$ & $\begin{array}{l}1.75^{\text {*** }} \\
(0.05)\end{array}$ & $\begin{array}{l}1.63^{\text {*** }} \\
(0.07)\end{array}$ & $\begin{array}{l}2.51^{\text {*** }} \\
(0.06)\end{array}$ & $\begin{array}{l}2.49^{* * *} \\
(0.07)\end{array}$ & $\begin{array}{l}2.13^{* * *} \\
(0.10)\end{array}$ \\
\hline Difference & $\begin{array}{c}0.14 \\
(0.08)\end{array}$ & $\begin{array}{c}0.22^{*} \\
(0.08)\end{array}$ & $\begin{array}{l}0.43^{* * *} \\
(0.10)\end{array}$ & $\begin{array}{l}0.25^{* * *} \\
(0.07)\end{array}$ & $\begin{array}{c}0.02 \\
(0.07)\end{array}$ & $\begin{array}{c}0.07 \\
(0.08)\end{array}$ & $\begin{array}{l}0.43^{* * *} \\
(0.08)\end{array}$ & $\begin{array}{l}0.51^{* * * *} \\
(0.09)\end{array}$ & $\begin{array}{l}1.03^{* * *} \\
(0.13)\end{array}$ \\
\hline $\begin{array}{l}\text { Decomposition } \\
\text { Explained }\end{array}$ & $\begin{array}{l}0.05^{*} \\
(0.02)\end{array}$ & $\begin{array}{l}0.12^{* * *} \\
(0.02)\end{array}$ & $\begin{array}{l}0.12^{* * *} \\
(0.02)\end{array}$ & $\begin{array}{l}0.05^{* * 1} \\
(0.02)\end{array}$ & - & - & $\begin{array}{c}0.03 \\
(0.02)\end{array}$ & $\begin{array}{l}0.15^{\text {*** }} \\
(0.03)\end{array}$ & $\begin{array}{c}0.07^{*} \\
(0.03)\end{array}$ \\
\hline Unexplained & $\begin{array}{c}0.09 \\
(0.08)\end{array}$ & $\begin{array}{c}0.09 \\
(0.08)\end{array}$ & $\begin{array}{l}0.31^{* *} \\
(0.10)\end{array}$ & $\begin{array}{l}0.20^{* *} \\
(0.06)\end{array}$ & - & - & $\begin{array}{l}0.40^{* * *} \\
(0.07)\end{array}$ & $\begin{array}{l}0.36^{* * *} \\
(0.09)\end{array}$ & $\begin{array}{l}0.97^{* * *} \\
(0.13)\end{array}$ \\
\hline Decomposition & percent & & & & & & & & \\
\hline Explained & $\begin{array}{c}33.56 \\
(19.26)\end{array}$ & $\begin{array}{c}56.47^{*} \\
(23.50)\end{array}$ & $\begin{array}{l}27.68^{* * *} \\
(8.08)\end{array}$ & $\begin{array}{l}20.14^{* *} \\
(7.63)\end{array}$ & - & - & $\begin{array}{c}7.13 \\
(4.93)\end{array}$ & $\begin{array}{l}28.90^{* * *} \\
(6.83)\end{array}$ & $\begin{array}{c}6.30^{*} \\
(2.91)\end{array}$ \\
\hline Unexplained & $\begin{array}{l}66.44^{* * *} \\
(19.26)\end{array}$ & $\begin{array}{c}43.53 \\
(23.50)\end{array}$ & $\begin{array}{l}72.32^{* * *} \\
(8.08)\end{array}$ & $\begin{array}{l}79.86^{* * *} \\
(7.63)\end{array}$ & - & - & $\begin{array}{l}92.87^{* * *} \\
(4.93)\end{array}$ & $\begin{array}{l}71.10^{* * *} \\
(6.83)\end{array}$ & $\begin{array}{l}93.70^{* * *} \\
(2.91)\end{array}$ \\
\hline Observations & 12112 & 11133 & 12665 & 12112 & 11133 & 12665 & 12112 & 11133 & 12665 \\
\hline Individuals & 2939 & 2594 & 2739 & 2939 & 2594 & 2739 & 2939 & 2594 & 2739 \\
\hline
\end{tabular}


Table 4. Oaxaca-Blinder Twofold Decomposition Results for the Predicted East-West Differences in Gender Ideologies: Comparing the Three Cohorts at Similar Age.

\begin{tabular}{|c|c|c|c|c|c|c|c|c|c|c|c|c|}
\hline & \multicolumn{4}{|c|}{ FemEmpl } & \multicolumn{4}{|c|}{ Housework } & \multicolumn{4}{|c|}{ MatEmpl } \\
\hline & $\begin{array}{c}\text { 1990s- } \\
\text { cohort: } \\
\text { age } 24-27 \\
\end{array}$ & $\begin{array}{c}\text { 1980s- } \\
\text { cohort: } \\
\text { age } 24-27 \\
\end{array}$ & 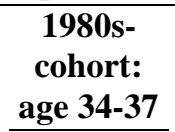 & $\begin{array}{c}\text { 1970s- } \\
\text { cohort: } \\
\text { age } 34-37\end{array}$ & $\begin{array}{c}\text { 1990s- } \\
\text { cohort: } \\
\text { age } 24-27 \\
\end{array}$ & 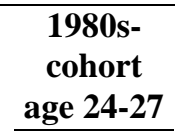 & $\begin{array}{c}\begin{array}{c}\text { 1980s- } \\
\text { cohort }\end{array} \\
\text { age } 34-37 \\
\end{array}$ & $\begin{array}{c}\text { 1970s- } \\
\text { cohort: } \\
\text { age } 34-37 \\
\end{array}$ & $\begin{array}{c}\text { 1990s- } \\
\text { cohort: } \\
\text { age } 24-27 \\
\end{array}$ & $\begin{array}{c}\text { 1980s- } \\
\text { cohort: } \\
\text { age } 24-27 \\
\end{array}$ & $\begin{array}{c}\text { 1980s- } \\
\text { cohort: } \\
\text { age } 34-37 \\
\end{array}$ & $\begin{array}{c}\text { 1970s- } \\
\text { cohort: } \\
\text { age } 34-37 \\
\end{array}$ \\
\hline & M1 & $\mathrm{M} 2$ & M3 & M4 & M1 & $\mathrm{M} 2$ & M3 & M4 & M1 & M2 & M3 & M4 \\
\hline $\begin{array}{l}\text { Differential } \\
\text { West }\end{array}$ & $\begin{array}{l}2.58^{* * * *} \\
(0.10)\end{array}$ & $\begin{array}{l}2.68^{* * * *} \\
(0.09)\end{array}$ & $\begin{array}{l}2.82^{* * *} \\
(0.10)\end{array}$ & $\begin{array}{l}3.00^{* * *} \\
(0.09)\end{array}$ & $\begin{array}{l}1.82^{* * *} \\
(0.08)\end{array}$ & $\begin{array}{l}1.65^{* * *} \\
(0.07)\end{array}$ & $\begin{array}{l}1.77^{\text {**** }} \\
(0.09)\end{array}$ & $\begin{array}{l}1.67^{* * * *} \\
(0.07)\end{array}$ & $\begin{array}{l}2.74^{* * *} \\
(0.11)\end{array}$ & $\begin{array}{l}3.11^{\text {*** }} \\
(0.09)\end{array}$ & $\begin{array}{l}3.17^{* * * *} \\
(0.08)\end{array}$ & $\begin{array}{l}3.32^{\text {**** }} \\
(0.11)\end{array}$ \\
\hline East & $\begin{array}{l}2.22^{* * * *} \\
(0.13)\end{array}$ & $\begin{array}{l}2.60^{* * * *} \\
(0.09)\end{array}$ & $\begin{array}{l}2.74^{* * * *} \\
(0.14)\end{array}$ & $\begin{array}{l}2.47^{* * *} \\
(0.12)\end{array}$ & $\begin{array}{l}1.37^{* * *} \\
(0.11)\end{array}$ & $\begin{array}{l}1.58^{* * *} \\
(0.07)\end{array}$ & $\begin{array}{l}1.88^{* * *} \\
(0.13)\end{array}$ & $\begin{array}{l}1.35^{* * *} \\
(0.09)\end{array}$ & $\begin{array}{l}2.28^{* * *} \\
(0.12)\end{array}$ & $\begin{array}{l}2.45^{* * *} \\
(0.10)\end{array}$ & $\begin{array}{l}2.13^{* * *} \\
(0.10)\end{array}$ & $\begin{array}{l}2.15^{* * *} \\
(0.13)\end{array}$ \\
\hline Difference & $\begin{array}{c}0.36^{*} \\
(0.16) \\
\end{array}$ & $\begin{array}{c}0.08 \\
(0.12) \\
\end{array}$ & $\begin{array}{c}0.09 \\
(0.17) \\
\end{array}$ & $\begin{array}{l}0.53^{* * *} \\
(0.15) \\
\end{array}$ & $\begin{array}{c}0.45^{* *} \\
(0.14) \\
\end{array}$ & $\begin{array}{c}0.07 \\
(0.10) \\
\end{array}$ & $\begin{array}{l}-0.11 \\
(0.16) \\
\end{array}$ & $\begin{array}{l}0.32^{* *} \\
(0.11) \\
\end{array}$ & $\begin{array}{l}0.46^{* *} \\
(0.16) \\
\end{array}$ & $\begin{array}{l}0.66^{* * * *} \\
(0.14)\end{array}$ & $\begin{array}{l}1.03^{* * *} \\
(0.13) \\
\end{array}$ & $\begin{array}{l}1.16^{* * * *} \\
(0.17)\end{array}$ \\
\hline $\begin{array}{l}\text { Decompositior } \\
\text { Explained }\end{array}$ & $\begin{array}{c}0.03 \\
(0.04)\end{array}$ & $\begin{array}{c}0.05 \\
(0.04)\end{array}$ & $\begin{array}{l}0.15^{\text {*** }} \\
(0.04)\end{array}$ & $\begin{array}{l}0.11^{* *} \\
(0.04)\end{array}$ & $\begin{array}{c}0.07^{*} \\
(0.03)\end{array}$ & $\begin{array}{c}0.07^{*} \\
(0.03)\end{array}$ & $\begin{array}{l}0.10^{* * *} \\
(0.03)\end{array}$ & $\begin{array}{l}0.08^{* * *} \\
(0.03)\end{array}$ & $\begin{array}{l}-0.01 \\
(0.04)\end{array}$ & $\begin{array}{l}0.14^{\text {*** }} \\
(0.04)\end{array}$ & $\begin{array}{c}0.07^{*} \\
(0.03)\end{array}$ & $\begin{array}{c}0.06 \\
(0.05)\end{array}$ \\
\hline Unexplained & $\begin{array}{c}0.33^{*} \\
(0.15)\end{array}$ & $\begin{array}{c}0.03 \\
(0.12)\end{array}$ & $\begin{array}{l}-0.07 \\
(0.17)\end{array}$ & $\begin{array}{l}0.42^{* *} \\
(0.15)\end{array}$ & $\begin{array}{l}0.38^{* *} \\
(0.13)\end{array}$ & $\begin{array}{l}-0.00 \\
(0.10)\end{array}$ & $\begin{array}{l}-0.22 \\
(0.16)\end{array}$ & $\begin{array}{c}0.24^{*} \\
(0.11)\end{array}$ & $\begin{array}{l}0.46^{* *} \\
(0.15)\end{array}$ & $\begin{array}{l}0.51^{* * *} \\
(0.14)\end{array}$ & $\begin{array}{l}0.97^{* * *} \\
(0.13)\end{array}$ & $\begin{array}{l}1.10^{* * *} \\
(0.17)\end{array}$ \\
\hline $\begin{array}{l}\text { Decompositior } \\
\text { Explained }\end{array}$ & $\begin{array}{l}\text { in percent } \\
7.06 \\
(9.23)\end{array}$ & $\begin{array}{c}65.52 \\
(95.67)\end{array}$ & $\begin{array}{l}173.75 \\
(327.31)\end{array}$ & $\begin{array}{l}21.31^{*} \\
(8.84)\end{array}$ & $\begin{array}{l}14.98^{*} \\
(6.96)\end{array}$ & $\begin{array}{c}100.93 \\
(138.80)\end{array}$ & $\begin{array}{c}-92.16 \\
(134.44)\end{array}$ & $\begin{array}{c}25.90^{*} \\
(10.91)\end{array}$ & $\begin{array}{l}-1.31 \\
(8.56)\end{array}$ & $\begin{array}{l}21.88^{* * *} \\
(6.45)\end{array}$ & $\begin{array}{c}31.84^{*} \\
(15.44)\end{array}$ & $\begin{array}{l}5.15 \\
(3.91)\end{array}$ \\
\hline Unexplained & $\begin{array}{l}92.94^{* * *} \\
(9.23)\end{array}$ & $\begin{array}{c}34.48 \\
(95.67)\end{array}$ & $\begin{array}{l}-73.75 \\
(327.31)\end{array}$ & $\begin{array}{l}78.69^{* * * *} \\
(8.84)\end{array}$ & $\begin{array}{l}85.02^{* * *} \\
(6.96)\end{array}$ & $\begin{array}{c}-0.93 \\
(138.80)\end{array}$ & $\begin{array}{c}192.16 \\
(134.44)\end{array}$ & $\begin{array}{l}74.10^{* * * *} \\
(10.91)\end{array}$ & $\begin{array}{c}101.31^{* * * *} \\
\quad(8.56)\end{array}$ & $\begin{array}{l}78.12^{* * *} \\
(6.45)\end{array}$ & $\begin{array}{l}68.16^{* * *} \\
(15.44)\end{array}$ & $\begin{array}{l}94.85^{* * *} \\
(3.91)\end{array}$ \\
\hline $\begin{array}{l}\text { Observation } \\
\text { Individuals }\end{array}$ & $\begin{array}{l}2279 \\
1443 \\
\end{array}$ & $\begin{array}{l}2778 \\
2140 \\
\end{array}$ & $\begin{array}{l}2363 \\
1469 \\
\end{array}$ & $\begin{array}{l}2989 \\
2349 \\
\end{array}$ & $\begin{array}{l}2279 \\
1443 \\
\end{array}$ & $\begin{array}{l}2778 \\
2140 \\
\end{array}$ & $\begin{array}{l}2363 \\
1469 \\
\end{array}$ & $\begin{array}{l}2989 \\
2349 \\
\end{array}$ & $\begin{array}{l}2279 \\
1443 \\
\end{array}$ & $\begin{array}{l}2778 \\
2140 \\
\end{array}$ & $\begin{array}{l}2363 \\
1469 \\
\end{array}$ & $\begin{array}{l}2989 \\
2349 \\
\end{array}$ \\
\hline
\end{tabular}

Notes: Standard errors clustered on individual level in parentheses. ${ }^{*} p<0.05,{ }^{* *} p<0.01,{ }^{* * *} p<0.001$ Source: pairfam $10.0(2008-2018)$ 